\title{
An alternative explanation of PMSE-like scatter in MF radar data
}

\author{
G. O. L. Jones ${ }^{1}$, M. A. Clilverd ${ }^{1}$, P. J. Espy ${ }^{1}$, S. Chew ${ }^{1}$, D. C. Fritts ${ }^{2}$, and D. M. Riggin ${ }^{2}$ \\ ${ }^{1}$ British Antarctic Survey, NERC, Madingley Road, Cambridge, CB3 OET, U.K. \\ ${ }^{2}$ Colorado Research Associates, a division of NorthWest Research Associates, 3380 Mitchell Lane, Boulder, CO 80301, USA
}

Received: 6 November 2003 - Revised: 19 March 2004 - Accepted: 5 May 2004 - Published: 7 September 2004

\begin{abstract}
There have been reports in the literature that spaced-antenna MF radars may provide a source of data on Polar Mesospheric Summer Echoes (PMSE). Even though the expected scatter from PMSE at MF frequencies is very much weaker than at VHF, the wide distribution of sites and long duration of data sets for MF radar systems could provide valuable information about the occurrence of PMSE. This paper tests whether there is any evidence of PMSE in the profiles derived using the MF radar at Rothera, Antarctica, one of the few such radars at high southern latitudes. Over a year of data during 1997/1998 has been analysed for the occurrence of persistent features around midday in the altitude range $60-95 \mathrm{~km}$. Criteria were chosen to test the likelihood that some of the narrow peaks in the power profiles were manifestations of electron density structures associated with PMSE. Although a small number of persistent features were seen at altitudes of $80-85 \mathrm{~km}$ that are typically associated with PMSE, there was no seasonality in their occurrence. A detailed analysis of specific days showed that two peaks were often seen with altitude separations consistent with the vertical wavelength of the diurnal tide. Persistent features were also detected at altitudes of $70 \mathrm{~km}$ and $90 \mathrm{~km}$ during the winter months, thus showing a quite different seasonality to that of PMSE. An estimate of the turbulence caused by the breaking of gravity waves that have propagated up from the lower atmosphere shows that at Rothera significant energy is deposited near $80 \mathrm{~km}$ during summer, and near 70 and $90 \mathrm{~km}$ during winter. This seasonal variability is driven by the screening effect of stratospheric winds, and it appears that breaking gravity wave dynamics, rather than PMSE phenomena, can explain many of the localised altitude features in the MF radar data.
\end{abstract}

Key words. Meteorology and atmospheric dynamics (Middle atmosphere dynamics; Turbulence; Instruments and techniques)

Correspondence to: M. A. Clilverd

(m.clilverd@bas.ac.uk

\section{Introduction}

Polar mesospheric summer echoes (PMSE) are observed at VHF as strong radar echoes near the altitude of the summer mesopause. Their occurrence is related to cold summer mesospheric temperatures (Cho and Kelley, 1993; Cho and Röttger, 1997) and this fact, along with their association with noctilucent clouds, has led to an interest in their possible use as an indicator of global climate change (Thomas, 1996). The echoes are persistent, often lasting for several hours, although their strength and vertical structure can vary considerably on timescales of minutes (Röttger et al., 1988). Most observations have been made in the northern hemisphere, particularly at high and mid-to-high latitudes, whereas in the southern hemisphere observations of PMSE are very sparse due to the scarcity of suitable radar systems. It has also been suggested (Balsley et al., 1995) that PMSE are weaker at southern latitudes due to hemispherical differences in the mesospheric temperature and/or water vapour content: weaker PMSE would make their observation less likely. Whilst commonly seen during the summer months at frequencies in the VHF band, and even at higher UHF frequencies (Röttger et al., 1990; Cho et al., 1992) any manifestations of PMSE are expected to be very much weaker at the lower MF frequencies on which this paper focuses. Nevertheless, there have been reports of PMSE-like scatter from a number of radars at frequencies of 2 to $4 \mathrm{MHz}$. Fraser and Khan (1990) first suggested the possible influence of PMSE on the fading of echoes observed by a $2 \mathrm{MHz}$ radar at Scott Base, Antarctica (77.8 S). A more detailed study by Bremer et al. (1996) extended the analysis of PMSE in MF radar signals by comparison with VHF radar signatures at $69.6^{\circ} \mathrm{N}$. Using a rather limited dataset they showed that strong peaks in the MF radar signal sometimes occurred at the same time as PMSE were seen by a nearby VHF radar. Despite what they called "strong hints that PMSE also occur at $2.78 \mathrm{MHz}$ ", Bremer et al. (1996) acknowledged the considerable variability of the partial reflection contribution to the profiles of scattered signals. Also, they did not present MF data from outside the PMSE season for comparison. Hoppe et al. (1990) had earlier used the same MF radar 


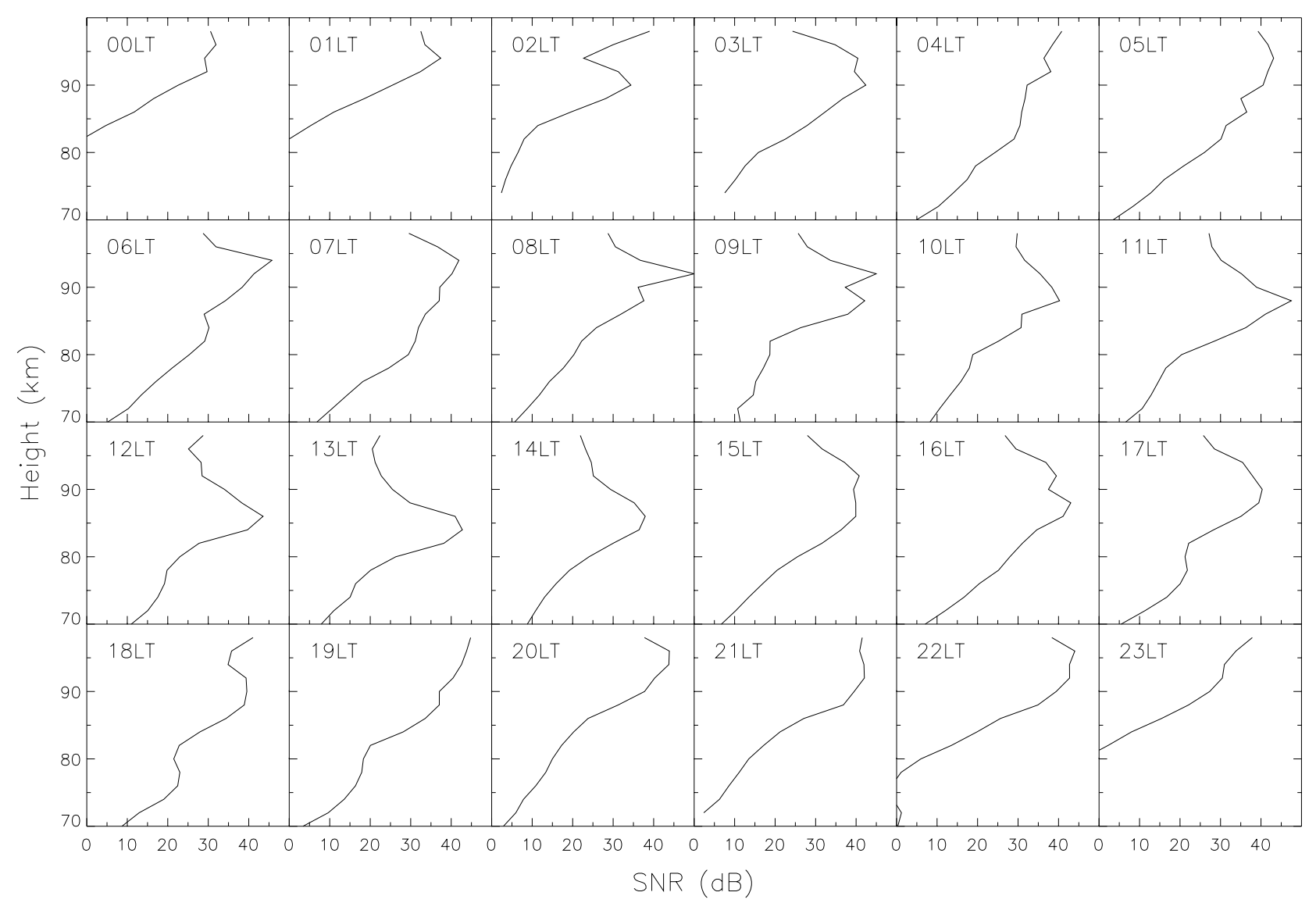

Fig. 1. The hourly averaged SNR profiles for 24 December 1997.

system during simultaneous PMSE measurements at VHF but had found no evidence of PMSE. More recently, Murphy and Vincent (2000) analysed several years of MF radar data from Davis, Antarctica, $\left(68.6^{\circ} \mathrm{S}\right)$ searching for amplitude enhancements. The peaks they identified at PMSE altitudes only occurred in a very small percentage of profiles $(<0.1 \%$ at $77 \mathrm{~km})$ and were short-lived, typically lasting 2 minutes or less. Nevertheless, they tentatively linked them to PMSE, principally because of their tendency to occur during the summer months.

In this study we analyse data from the $1.96 \mathrm{MHz} \mathrm{MF}$ radar at Rothera, a high-latitude southern-hemisphere site $\left(67.5^{\circ} \mathrm{S}\right.$, $68.0^{\circ} \mathrm{W}$ ). We test for the occurrence of persistent enhancements in profiles of radar signal to noise ratio (SNR), calculated using the full correlation analysis technique (SA-FCA, Gregory and Manson, 1975), that last for 15-30 min as might be expected from a signature associated with PMSE. The analysis uses a filter algorithm to detect soundings that exhibit peaks in the signal above the normal background profile, looking particularly for features with a narrow vertical structure. Data was gathered from March 1997 to October 1998, centred on the austral summer (the best season for PMSE occurrence) and based on soundings recorded at 3-min intervals. The data set is examined for the occurrence of any PMSE-related enhancements as well as for annual trends or seasonal differences.

\section{Peaks in SNR profiles}

Partial reflection signals from the mesosphere at $1.96 \mathrm{MHz}$ are very variable with both height and with time. In general, the SNR increases with altitude as the electron concentration increases through the D-region. However, the changing effects of solar illumination, particle precipitation and dynamical influences introduce a large degree of variability (Manson and Meek, 1989). In this first section we exhibit two case studies from the Rothera MF radar showing the variation in SNR profiles during a typical day. The presentation format is similar to that used by Bremer et al. (1996) who compared hourly MF profiles with simultaneous observations of PMSE made using a VHF radar. Figure 1 shows mean hourly profiles of SNR from the Rothera MF radar on 24 December 1997. The expected increase in SNR with altitude is clearly seen in profiles throughout the day, but here we focus on the occurrence of narrow peaks in the profiles and their variability from hour-to-hour.

Between 00:00-02:00 LT low SNR values are seen at heights below $82 \mathrm{~km}$ and high SNR at heights above $90 \mathrm{~km}$. A peak evolves at $94 \mathrm{~km}$ around 06:00 LT, with evidence of a secondary ledge structure at $82 \mathrm{~km}$. The high peak drops in altitude to $88 \mathrm{~km}$ by $11: 00 \mathrm{LT}$ and $85 \mathrm{~km}$ by $13: 00$ LT. This peak then persists at this height until 15:00 LT, whereupon it appears to widen while the altitude increases slightly. 


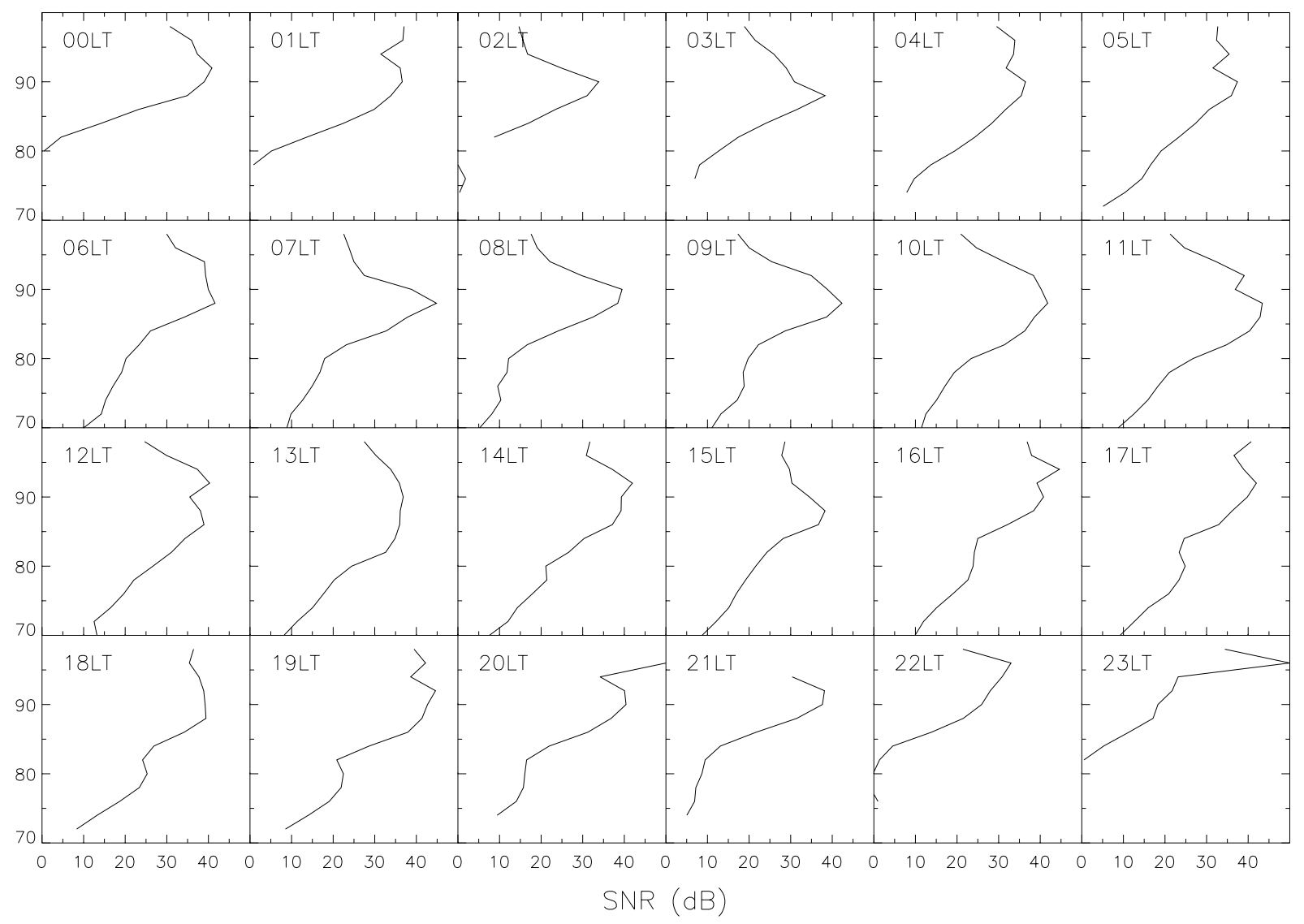

Fig. 2. The hourly averaged SNR profiles for 16 January 1998.

A separate ledge near $76 \mathrm{~km}$ forms at 17:00 LT, lasting until at least 20:00 LT. During this period the two peaks exist concurrently with a vertical separation of about $14 \mathrm{~km}$, a distance consistent with the vertical wavelength of the diurnal tide Forbes (1985). The SNR peaks shown here are remarkably similar to those described by Bremer et al. (1996) as coinciding with strong PMSE seen simultaneously at VHF (see their Fig. 5). Whilst we do not have a co-located VHF radar for comparison, we have extended our study at Rothera to many more days of MF radar data in order to allow a statistical study of the SNR peaks and to assess their occurrence against PMSE criteria.

A second example in Fig. 2 shows a very similar set of profiles, this time from 16 January 1998. On this day a wide peak persists for most of the day. Over the local noon period of 11:00-13:00 LT it is a wide curve with smaller sub-peaks at 86 and $92 \mathrm{~km}$. These persist until 14:00 LT when the beginning of a ledge structure at $78 \mathrm{~km}$ is also seen, becoming fully formed by 17:00 LT at altitudes of $80 \mathrm{~km}$ and persisting until 20:00 LT. Once again the altitude separation of the two concurrent peaks is in the expected tidal wavelength range of $10-15 \mathrm{~km}$. In fact, the similarity in the nature of the twin peaks in Figures 1 and 2 is suggestive of a common influence such as tidal activity, as will be discussed later.
In order to automate the identification of peak features within the MF radar dataset, the average monthly SNR profiles were first derived for use as a reference against which peaks in the individual profiles could be identified. The investigation was confined to the period centred on local midday, 11:00-13:00 LT (15:00-17:00 UT) which is commonly regarded as the most likely time to observe the strongest PMSE (Palmer et al., 1994). Once the background profile was known, an algorithm was applied to the data to look for enhancements in SNR and to identify a peak. The criteria used to identify such a peak were similar to those used by Murphy and Vincent (2000) except that here we test for longer-lived events:

1. The enhancement should exceed the background profile by $>3 \mathrm{~dB}$.

2. A peak must occur within a set height range, typically between 60 and $95 \mathrm{~km}$. Any PMSE-like echoes would be expected to occur near $82 \mathrm{~km}$ (Cho and Röttger, 1997).

3. Peaks should persist in time so as to be present in at least $50 \%$ of the profiles within a half-hour interval. This test was added to eliminate spurious short-lived peaks, where there is a poor SNR measurement due to 


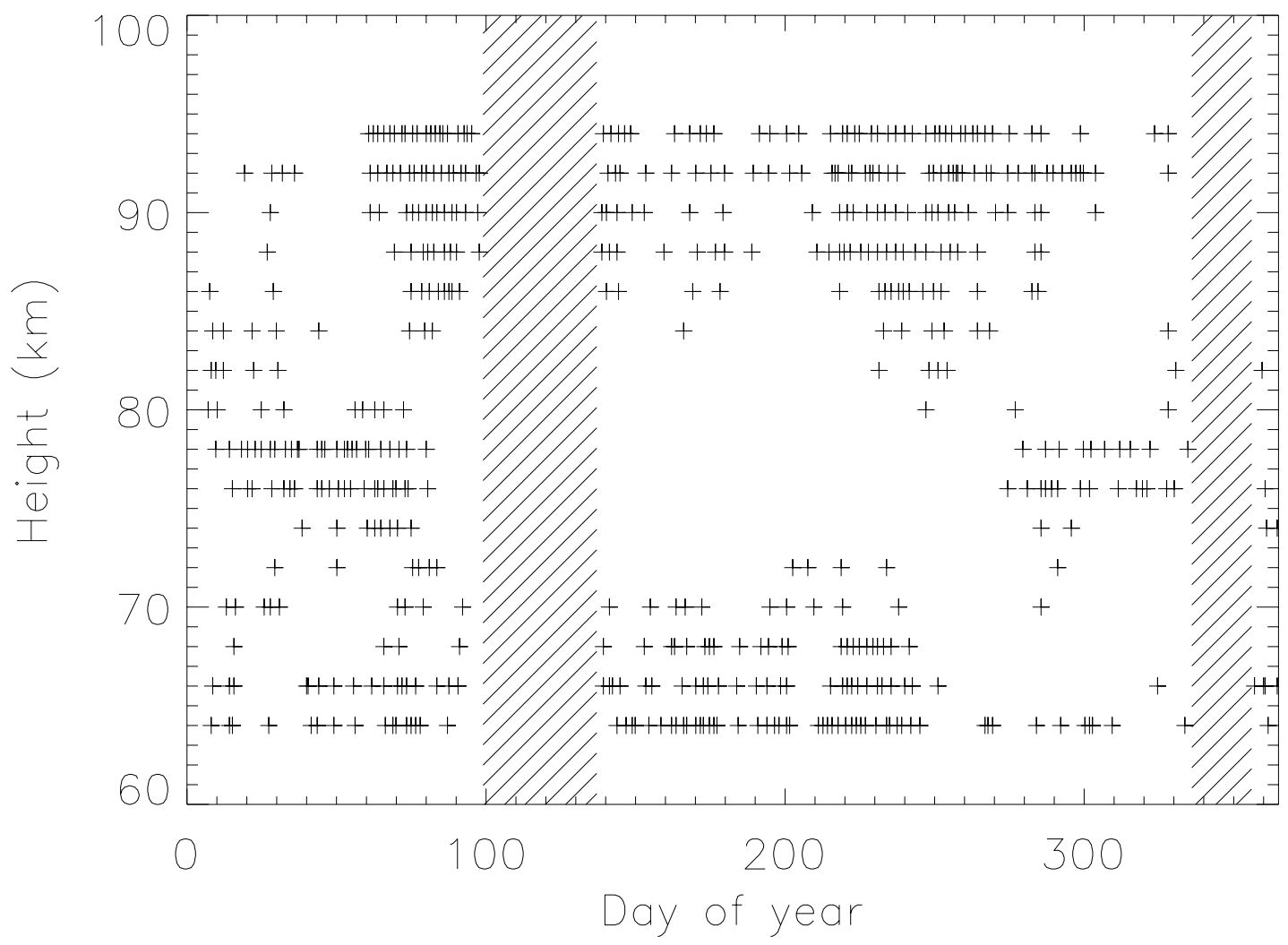

Fig. 3. The annual variation of peak heights for persistent events, showing the three preferred heights bands at $65 \mathrm{~km}, 77 \mathrm{~km}$, and $90 \mathrm{~km}$. (Shaded sections represent gaps in the available data)

the effects of noise or meteors, and to select features with similar temporal characteristics to PMSE.

Figure 3 shows the annual distribution of SNR peaks detected using this algorithm, with individual peaks represented by a small cross. Three preferred heights are apparent near $65 \mathrm{~km}, 77 \mathrm{~km}$ and $90 \mathrm{~km}$, each having different number densities and seasonal distributions. There is strong preference towards summer in the occurrence of peaks at PMSE heights of $80-85 \mathrm{~km}$, but the numbers in this height range are less than in the preferred height bands above and below. In terms of the actual percentage of days in each month for which peak features were found at each height, percentage occurrence levels were low, typically $<5 \%$. However, during the southern hemisphere summer months the occurrence levels rose to $15-20 \%$ at altitudes of $78 \mathrm{~km}$. Whilst the peaks at altitudes near $76 \mathrm{~km}$ show seasonal behaviour, biased towards the summer months, the altitudes associated with PMSE occurrence $(82 \mathrm{~km})$ have a relatively low peak occurrence rate and show little seasonality.

Further confirmation of the lack of direct association between specific peak features at MF and the presence of PMSE was suggested by provisional results from a short campaign of simultaneous PMSE observations at VHF. For ten days during February 1998, a ship-borne VHF radar made observations in the vicinity of Rothera (R. F. Woodman, personal communication). A qualitative assessment of the re- sults showed no obvious correlation between the dates and times on which PMSE were seen by this VHF radar and those when peak features were seen by the Rothera MF radar.

\section{Discussion}

In the Rothera MF data we find that there are several preferred altitudes at which persistent peaks are observed. This finding is consistent with the work of Schlegel et al. (1977) who used the $2.75 \mathrm{MHz}$ radar at Tromso $\left(69.6^{\circ} \mathrm{N}\right)$ and found three distinct height regions where stronger scatter was received, namely $65 \mathrm{~km}, 75 \mathrm{~km}$, and $83 \mathrm{~km}$. The measurements were made during the northern hemisphere summer of 1975 . The preferred altitudes were inferred to be associated with solar radiation influences (upper altitude region) and thermodynamical effects of the neutral atmosphere (lower altitude region). The preferred altitude ranges were expected to exhibit annual height variations of $2-4 \mathrm{~km}$ which would be impossible to resolve accurately with the MF radar's restricted height resolution. However, such a height variation alone does not explain the presence of the third preferred height band near $75 \mathrm{~km}$. As shown by the Rothera results, it is this third band that shows the most significant annual variation, with peaks only occurring between the months of September to March, i.e. the austral summer months. 
A similar summer-dominated occurrence pattern of peak features has been reported by Murphy and Vincent (2000). They used a negative gradient detection algorithm to identify peaks in MF radar echoes at Davis, Antarctica $\left(68.5^{\circ} \mathrm{S}\right)$. The vast majority of their peaks were observed close to local midday, a finding which adds weight to the selection of that time interval in this work. Whilst the seasonal variation of the results is similar to ours, the peaks selected by Murphy and Vincent (2000) were mostly of very short duration, typically only a few minutes, with even the longest event at $77 \mathrm{~km}$ altitude lasting only 13 minutes. The algorithm we used to search the data at Rothera was chosen to identify the largerscale peak features such as those illustrated in Figs. 1 and 2. This required a much longer time persistence of $30 \mathrm{~min}$, and in practice the chosen events often lasted even longer than this. Nevertheless, by allowing the SNR peaks to fluctuate in amplitude during the 30 minute selection interval, any shortlived but repetitive events would also be selected. Another difference from the results of Murphy and Vincent (2000) was that their short-lived events tended to occur at altitudes that were 3-4 km higher than the persistent events at Rothera. This may be due to the efficacy of the Murphy and Vincent (2000) algorithm at different altitudes, or the different geographical location of the Davis radar.

One possible cause of peaks in the radar SNR profile is the effects of deposition of energy that has propagated up from the lower atmosphere (Fritts et al., 2003). The breaking gravity waves can produce turbulence that will create density fluctuations that reorganise the ionisation profiles locally. Even taking into account the smoothing due to the $\sim 4 \mathrm{~km}$ height resolution of the MF radar, and the fact that localised turbulence does not always produce associated refractive index variations and enhanced backscatter (Gibson-Wilde et al., 2000), we would expect to see evidence of such an effect in the statistical distribution of SNR peaks. The climatological altitude distribution and seasonal behaviour of the turbulent diffusion generated by gravity waves may be estimated using the expression given by Garcia and Solomon (1985):

$K_{z z}=\gamma \cdot k \frac{(\bar{u}-c)^{4}}{N^{3}}\left(\frac{1}{2 H}-\frac{3 \partial \bar{u} / \partial z}{2(\bar{u}-c)}\right)$

Here, $\gamma$ is an "efficiency" factor that accounts for the probability that the waves will not be present at all times, and is taken to be 0.12 (Garcia and Solomon, 1985). The zonal or meridional wave number of the gravity waves is given by $k$, which is assumed to be a constant $100 \mathrm{~km}$ for all the waves in the distribution (Garcia and Solomon, 1985). The zonal or meridional phase speed of these waves is given by $c$, and the scale height, $H$, the Brunt-Väisäillä frequency, $N$, and the mean zonal or meridional wind, $\bar{u}$, are evaluated at each altitude, $z$, for which the turbulent diffusion is to be calculated. This expression was used to roughly estimate the turbulent diffusion generated by gravity waves over the 65 to $105 \mathrm{~km}$ region by considering only the zonal wind component, and by assuming an initial phase-speed distribution for the waves near $10 \mathrm{~km}$ that is constant between $\pm 70 \mathrm{~m} / \mathrm{s}$ (Alexander and Rosenlof, 1996).

Gravity waves propagating upward from below will not reach heights above which their phase velocity matches the mean wind velocity. To account for this, the $5 \mathrm{~km}$ vertical resolution CIRA-86 model (Fleming et al. 1990) was used on a monthly basis to eliminate those waves from the distribution reaching each $5 \mathrm{~km}$ altitude interval between 65 and $105 \mathrm{~km}$. The remaining waves were integrated in equation 1 to estimate the relative turbulent diffusion at each altitude in the range during each month. This procedure did not account for seasonal changes in the gravity-wave spectrum, characteristic horizontal scales or the strength of gravity wave sources. However, Alexander (1998) has shown that the background wind filter can reproduce the geographical, seasonal and vertical variations in gravity-wave observations without any variations in the spectrum or amplitude of gravity wave sources in the troposphere. Thus, it would appear to be adequate to estimate the relative seasonal variations in the altitude profile of gravity-wave generated turbulent diffusion for comparison with the MF radar enhancements. The calculated mean monthly profiles of turbulent diffusion will indicate those regions and periods of high gravity-wave activity. However, since gravity-wave processes are intermittent, one would then expect more peaks, or perturbations to the mean monthly SNR profile of the MF radar in those regions.

The altitude distribution of wave-generated diffusion, subject to the constraints described above, is shown in Fig. 4 as a function of season. Here we see that the southernhemisphere winter region (centred on day number 172) is characterized by large values of wave-generated turbulent diffusion extending up through $95 \mathrm{~km}$. Thus it would appear that the winter solstice period is characterized by stronger mesospheric winds that interact with the waves to create turbulent diffusion that both heats the ambient atmosphere and enhances vertical mixing. During the late winter (e.g. day 225) there are two distinct heights of maximum diffusion, one near $90 \mathrm{~km}$ and one below $70 \mathrm{~km}$. It is these same height bands that contain the most SNR peaks during the winter season, as shown in Fig. 3. Conversely, during the summer season (e.g. day 0/365), it is clear from Fig. 4 that the bulk of turbulent diffusion is generated below $80 \mathrm{~km}$. The height of this feature also coincides with the summertime band of SNR peaks that are seen in Fig. 3. To emphasise this connection, the average summertime profiles of SNR peak occurrence and turbulent diffusion are overlaid in Fig. 5. The largest occurrence of SNR peaks is seen to be concentrated near $78 \mathrm{~km}$ showing how the height of the MF peak features correlate closely with the height of maximum turbulent diffusion. In addition to the wave-generated diffusion, tidal-driven turbulence can also produce density fluctuations (causing greater MF scatter) in a similar way. This could explain the altitudespaced peaks that were illustrated in Figs. 1 and 2 and whose separation corresponds to the expected vertical wavelength of the diurnal tide. 


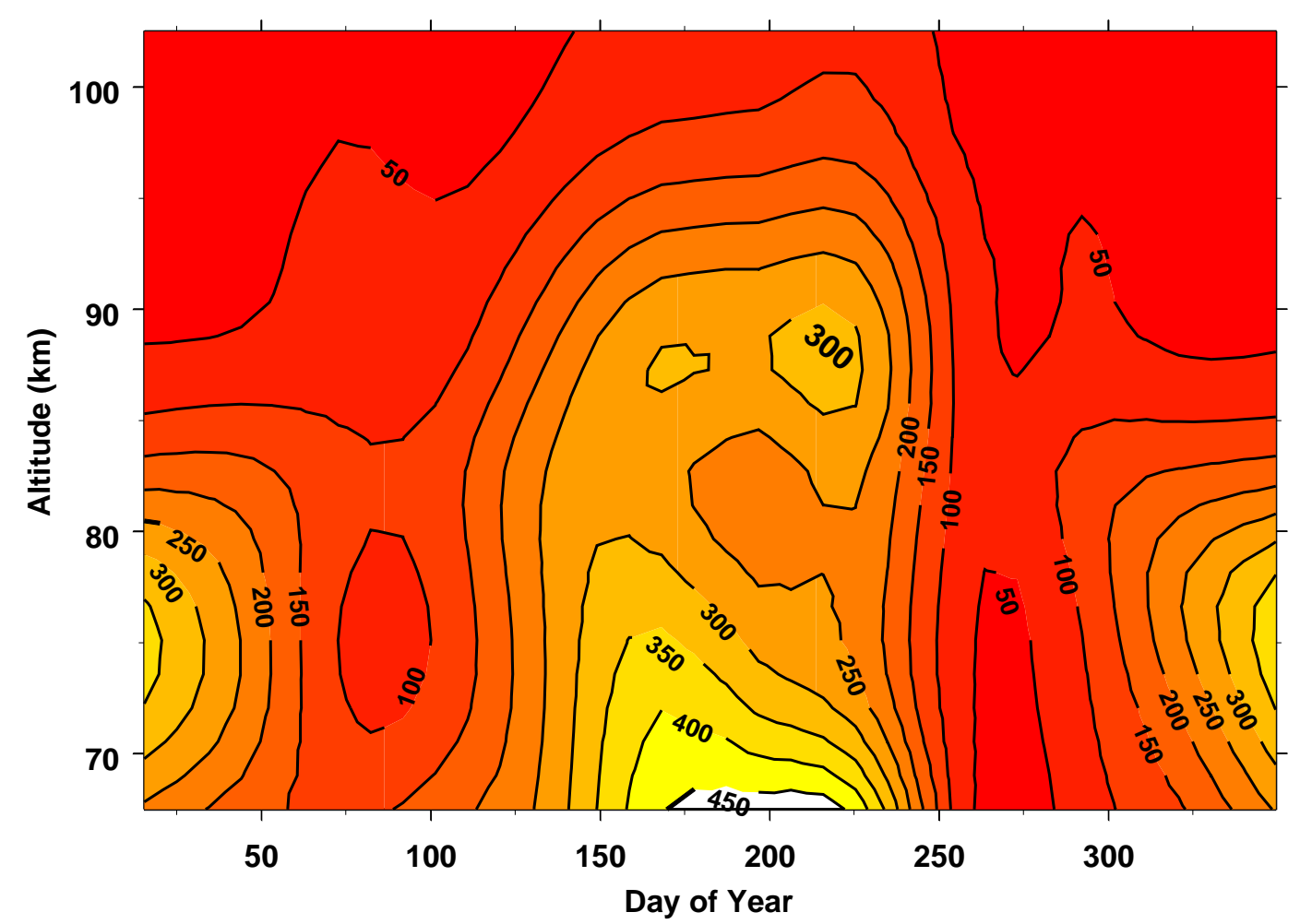

Fig. 4. The annual variation in the total turbulent diffusion at $70^{\circ} \mathrm{S}$ generated by gravity wave sources propagating upwards from $10 \mathrm{~km}$ altitude. Contours are in units of $\mathrm{m}^{2} \mathrm{~s}^{-1}$

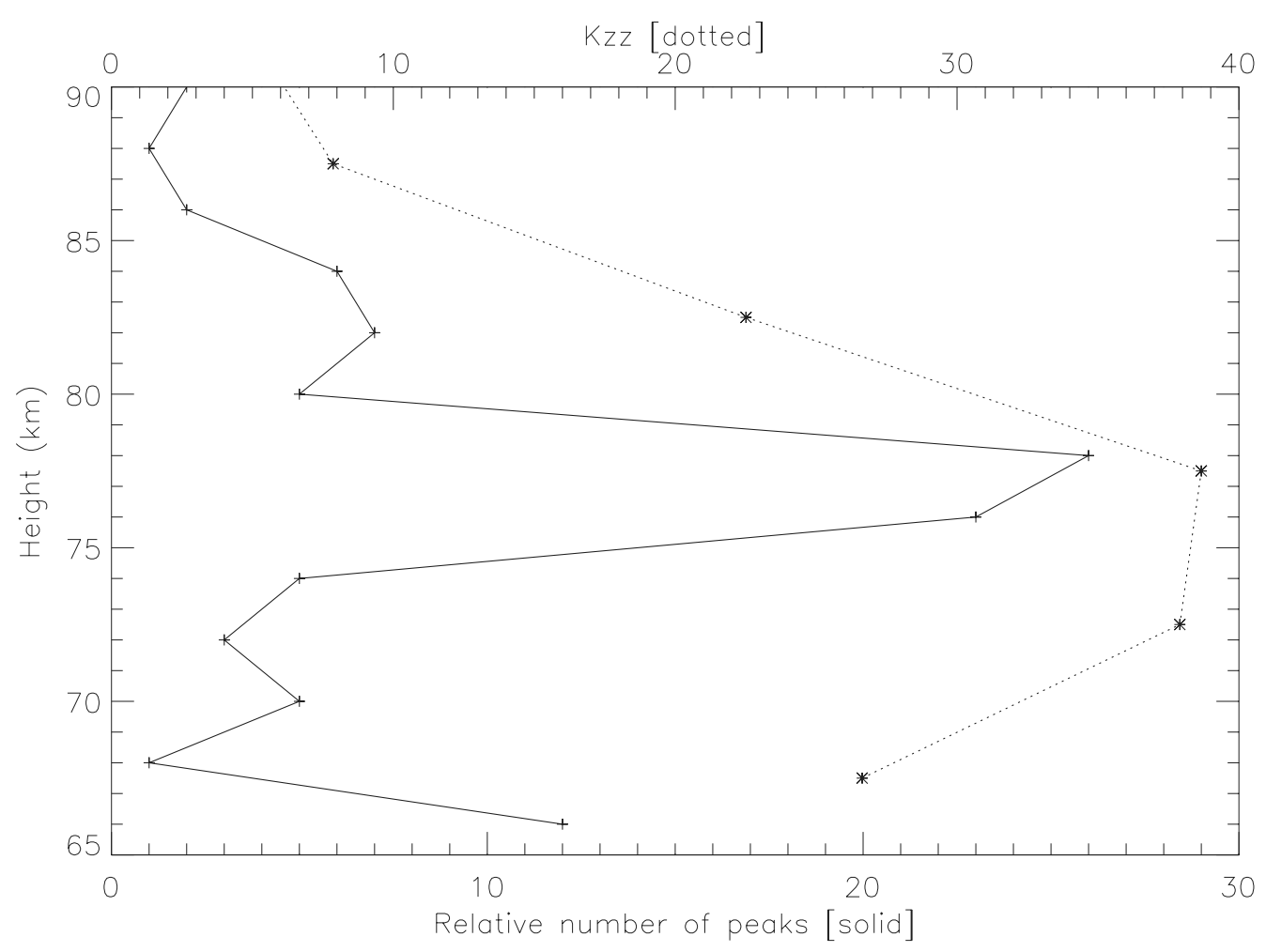

Fig. 5. Summertime profile of the estimated turbulent diffusion, $\mathrm{K}_{z z}$ (solid line), with a superimposed profile showing the corresponding number of SNR peaks (dotted line) observed during the summer months (NDJ) 


\section{Summary}

We have analysed data from the $1.96 \mathrm{MHz}$ radar at Rothera for the occurrence of persistent SNR peaks around midday in order to test the possibility that PMSE features could be detected at low, MF radar frequencies. Although peaks were found at PMSE altitudes, these features were seen during both summer and winter months, and the occurrence rates in both seasons were smaller than for similar features at other non-PMSE altitudes. Significant occurrence rates were found for peaks below $80 \mathrm{~km}$ during the summer months, a small number of which coincided with simultaneous peaks at higher altitudes. The statistics of their occurrence suggest that most of these features are unlikely to be linked to PMSE.

Analysis of specific days during the summer shows that SNR peaks sometimes occur at two altitudes simultaneously, with an altitude separation of about $12 \mathrm{~km}$. This separation is consistent with the vertical wavelength of the diurnal tide suggesting a dynamic, tidal influence on their creation. During the equinoxes large numbers of peaks were detected at higher altitudes of $90-100 \mathrm{~km}$. These features appear as broad ledges covering a large range of altitudes and are probably caused by enhanced ionisation levels associated with high geomagnetic activity.

A climatological estimate of the turbulence at $70^{\circ} \mathrm{S}$ caused by breaking gravity waves that have propagated up from lower altitudes shows that significant energy is deposited at $80 \mathrm{~km}$ during the summer months and at 70 and $90 \mathrm{~km}$ during the winter months. This seasonal variability is driven by the screening effect of stratospheric winds and the interaction of the remaining waves with the mesospheric wind field. There is a strong correlation between these seasonal changes in turbulence and the height of persistent peaks in MF SNR profiles suggesting that enhanced turbulence is influencing the increased radar scatter. Thus it appears that turbulence resulting from breaking gravity waves can explain many of the persistent peak features in the MF radar data, whereas no clear link can be forged with PMSE.

Acknowledgements. The Rothera MF radar was jointly supported by the US National Science Foundation grants OPP-9319068 and OPP-9813629 and by the UK Natural Environment Research Council.

Topical Editor U.-P. Hoppe thanks D. Holdsworth and C. Hall for their help in evaluating this paper.

\section{References}

Alexander, M. J.: Interpretations of observed climatological patterns in stratospheric gravity wave variance, J. Geophys. Res., 103, 8627-8640, 1998.

Alexander, M. J. and Rosenlof, K. H.: Nonstationary gravity wave forcing of the stratospheric mean wind. J. Geophys. Res., 101, 23 465-23 474, 1996.

Bremer, J., Hoffman, P., Manson, A. H., Meek, C. E., Ruster, R., and Singer, W.: PMSE observations at three different frequencies in northern Europe during Summer 1994: Ann. Geophys. 14, 1317-1327, 1996.
Balsley, B. B. and Huaman, M.: On the relationship between seasonal occurrence of Northern Hemispheric polar mesosphere summer echoes and mean mesopause temperatures, J. Geophys. Res., 102, 2021-2024 1997.

Balsley, B. B., Woodman, R. F., Sarango, M., Urbina, J., Ragaini, E., Carey, J., Huaman, M., and Giraldez, A.: On the lack of southern-hemisphere polar mesosphere summer echoes, J. Geophys. Res., 100, $11685-11693,1995$.

Cho, J. Y. N., Kelley, M. C., and Heinselman, C. J.: Enhancement of Thomson scatter by charged aerosols in the polar mesosphere: measurements with a $1.29 \mathrm{MHz}$ radar, Geophys. Res. Lett., 19, 1097-1100, 1992.

Cho, J. Y. N. and Kelley, M. C.: Polar Mesosphere Summer radar Echoes: Observations and current theories, Rev. Geophys., 31, 243-265, 1993.

Cho, J. Y. N. and Röttger, J.: An updated review of polar mesosphere summer echoes: Observation, theory, and their relationship to noctilucent clouds and subvisible aerosols, J. Geophys. Res., 102, 2001-2020, 1997.

Espy, P. J. and Stegman, J.: Trends and variability of mesospheric temperatures at high latitudes, Phys. Chem. Earth, (6-8), 543553, 2002.

Fleming, E. L., Chandra, S., Barnett, J. J., and Corney, M.: Zonal mean temperature, pressure, zonal wind, and geopotential height as functions of latitude, COSPAR International Reference Atmosphere: 1986, Part II: Middle Atmosphere Models. Adv. Space Res. 10, 11-59, 1990.

Forbes, J. M.: MST radar detection of middle atmosphere tides, Radio Sci., 20, 1435-1440, 1985.

Fraser, G. J. and Khan, U.: Semidiurnal variations in the time scale of irregularities near the Antarctic summer mesopause, Radio Sci., 25, 997-1003, 1990.

Fritts, D. C., Bizon, C., Werne, J. A., and Meyer, C. K.: Layering accompanying turbulence generation due to shear instability and gravity wave breaking, J. Geophys. Res. Atmos., 108, (D8), 8452-8465, 2003.

Garcia, R. R. and Solomon, S.: A numerical-model of the zonally averaged dynamical and chemical-structure of the middle atmosphere, J. Geophys. Res., 88, 1379-1400, 1983.

Garcia, R. R., and Solomon, S.: The effect of breaking gravity waves on the dynamics and chemical composition of the mesosphere and lower thermosphere. J. Geophys. Res., 90, 38503868, 1985.

Gibson-Wilde, D. E., Werne, J. A., Fritts, D. C., and Hill, R. J.: Direct numerical simulation of VHF radar measurements of turbulence in the mesosphere, Rad. Sci., 35, 783-798, 2000.

Gregory, J. B. and Manson, A. H.: Winds and wave motions to $110 \mathrm{~km}$ at mid-latitudes, II, Mean winds at $52^{\circ} \mathrm{N}, 1969-1973$, J. Atmos. Sci., 32, 1667-1675, 1975.

Holton, J. R.: The role of gravity wave induced drag and diffusion in the momentum budget of the mesosphere. J. Atmos. Sci., 39, 791-799, 1982.

Holton, J.: The influence of gravity wave breaking on the general circulation of the middle atmosphere. J. Atmos. Sci., 40, $2497-$ 2507, 1983.

Hoppe, U. -P., Fritts, D. C., Reid, I. M., Czechowsky, P., Hall, C. M., and Hansen, T. L.: Multiple-frequency studies of the highlatitude summer mesosphere: implications for scattering processes. J. Atmos. Terr. Phys., 52, 907-926, 1990.

Kelley, M. C., Huaman, M., Chen, C. Y., and Ramos, C.: Polar Mesosphere Summer Echo observations at HF frequencies using the HAARP Gakona Ionospheric Observatory, Geophys. Res. 
Lett., 29, 10.1029/2001GL013411, 2002.

Lindzen, R. S.: Turbulence and stress owing to gravity wave and tidal breakdown. J. Geophys. Res., 86, 9707-9714, 1981.

Manson, A. H. and Meek, C. E.: Heights of MF radar scatter (1986/87) and the wind field (55-95 km): Saskatoon, Canada, J. Atmos. Terr. Phys., 51, 1003-1016, 1989.

Murphy, D. J. and Vincent, R. A.: Amplitude enhancements in Antarctic MF radar echoes, J. Geophys. Res., 105, 2668326 693, 2000.

Palmer, J. R., Rishbeth, H., Jones, G. O. L., Williams, P. J. S.: A statistical study of polar mesosphere summer echoes observed by EISCAT, J. Atmos. Terr. Phys., 58, 307-315, 1994.

Röttger, J., La Hoz, C., Kelley, M. C., Hoppe, U. -P., and Hall, C.: The structure and dynamics of Polar mesosphere Summer Echoes observed with the EISCAT 224 MHz radar, Geophys. Res. Lett., 15, 1353-1356, 1988.

Röttger J., Rietveld, M. T., La Hoz, C., Hall, T., Kelley, M. C., and Swartz, W. E.: Polar Mesosphere Summer Echoes observed with the EISCAT $933 \mathrm{MHz}$ radar and the CUPRI 46.9 MHz radar, their similarity to $224 \mathrm{MHz}$ radar echoes, and their relation to turbulence and electron density profiles, Radio Sci., 25, 671-687, 1990.
Schlegel, K., Brekke, A., Haug, A.: Some characteristics of the quiet polar D-region and mesosphere obtained with the partial reflection method, J. Atmos. Terr. Phys., 40, 205-213, 1977.

Thomas, G. E.: Global change in the mesosphere lower thermosphere region: has it already arrived? J. Atmos. Terr. Phys., 58, 1629-1656, 1996.

Woodman, R. F., Balsley, B. B., and Aquino, F., Rodriguez, R. R., and Flores, L. A.: First observations of polar mesosphere summer echoes in Antarctica, J. Geophys. Res., 104, 22 577-22 590, 1999.

Woodman, R. F., Sarango, M. F., and Soldi, H.: Mesospheric and ionospheric research using a ship-borne VHF radar, Proceedings of the 9th International Workshop on Technical and Scientific Aspects on MST Radar - MST9, 13-17 March, Toulouse, France, 2000. 